\title{
Seasonal Variation of GPS-Derived the Principal Ocean Tidal Constituents' Loading Displacement Parameters Based on Moving Harmonic Analysis in Hong Kong
}

\author{
Maosheng Zhou ${ }^{1}$, Xin Liu ${ }^{1, *}$, Jiajia Yuan ${ }^{1}$, Xin Jin $^{1}$, Yupeng Niu ${ }^{1}$, Jinyun Guo ${ }^{1} \mathbb{D}$ and Hao Gao ${ }^{1,2}{ }^{\mathbb{D}}$ \\ 1 College of Geodesy and Geomatics, Shandong University of Science and Technology, Qingdao 266590, China; \\ zhoumaosheng2018@sdust.edu.cn (M.Z.); yuanjiajia2017@sdust.edu.cn (J.Y.); \\ skdjinxin1010@sdust.edu.cn (X.J.); yupengniu1@163.com (Y.N.); guojy@sdust.edu.cn (J.G.); \\ gaohao88_sdioi@qlu.edu.cn (H.G.) \\ 2 Institute of Oceanographic Instrumentation, Qilu University of Technology (Shandong Academy of Sciences), \\ Qingdao 266061, China \\ * Correspondence: skd994268@sdust.edu.cn; Tel.: +86-0532-86057276
}

check for updates

Citation: Zhou, M.; Liu, X.; Yuan, J.; Jin, X.; Niu, Y.; Guo, J.; Gao, H. Seasonal Variation of GPS-Derived the Principal Ocean Tidal

Constituents' Loading Displacement Parameters Based on Moving Harmonic Analysis in Hong Kong. Remote Sens. 2021, 13, 279. https:// doi.org/10.3390/rs13020279

Received: 17 December 2020 Accepted: 12 January 2021 Published: 14 January 2021

Publisher's Note: MDPI stays neutral with regard to jurisdictional clai$\mathrm{ms}$ in published maps and institutional affiliations.

Copyright: (C) 2021 by the authors. Licensee MDPI, Basel, Switzerland. This article is an open access article distributed under the terms and conditions of the Creative Commons Attribution (CC BY) license (https:// creativecommons.org/licenses/by/ $4.0 /)$.

\begin{abstract}
The classical harmonic analysis (CHA) method only can be used to obtain the harmonic constants (amplitude and phase) of ocean tide loading displacement (OTLD). In fact, there are significant seasonal variations in the harmonic constants of OTLD. A moving harmonic analysis (MHA) method is proposed, which can effectively capture the seasonal variation of OTLD parameters. Based on 5 years of kinematic coordinate time series in direction U of six Global Positioning System (GPS) stations in Hong Kong, the MHA method is used to explore the seasonal variation of the OTLD parameters of the 6 principal tidal constituents (M2, S2, N2, K1, O1, Q1). The influence of mass loading on the seasonal variation of OTLD parameters is analyzed. The results show that there are obviously seasonal variations in OTLD parameters of the 6 principal tidal constituents in Hong Kong. The OTLD's amplitude's changes of the 6 principal tidal constituents are around $4-25.1 \%$ and the oscillation ranges of OTLD's phase parameters vary from $8.8^{\circ}$ to $20.4^{\circ}$. Among the seasonal variations of OTLD parameters, the annual signal, the semi-annual signal, and the ter-annual signal are the most significant. By analyzing the influence of atmospheric loading on the seasonal variation of OTLD parameters, it is found that atmospheric loading has certain contribution to the seasonal variation of OTLD parameters. Hydrological loading and non-tidal ocean loading have little influence on the seasonal variation of OTLD parameters.
\end{abstract}

Keywords: ocean tide loading displacement; seasonal variation; GPS; mass loading; Hong Kong

\section{Introduction}

Tidal forces can deform the earth, causing solid earth tide and ocean tide. The periodic redistribution of ocean mass due to ocean tide results in a periodic loading of the solid earth known as ocean tide loading (OTL) [1,2]. Most of the methods to estimate the ocean tide loading displacement (OTLD) are to obtain the harmonic constants (amplitude and phase) of each tide constituent by classical harmonic analysis (CHA) [3-6]. Many studies have found that the harmonic constants of each tide constituent have significant seasonal variation rather than a constant value [7-10], which will also indirectly lead to the seasonal variation of OTLD parameters. With the advancement of science and technology, the effect of OTL has become more and more widely used in the global navigation satellite system (GNSS), geodesy, ocean dynamics, geophysics, and geodynamics. The requirements for its accuracy are getting higher and higher [11]. When performing precise data processing, the seasonal variation of OTLD parameters is also an important factor to be considered.

The OTL is usually obtained by discrete convolution integration of tide height data using the Green function based on the earth model. Due to the wide application of 
GNSS in geodesy, coastal GNSS stations are sensitive to ocean tide, and the "deviations" caused by the OTL can also be accurately obtained through GNSS observations [12,13]. Penna et al. [13] showed that postprocessed kinematic precise point positioning (PPP) with appropriately tuned process noise constraints is capable of recovering synthetic tidal displacements inserted into real data, with a typical accuracy of $0.2 \mathrm{~mm}$ depending on the time series noise. The PPP technique is used to estimate OTLD parameters in the Antarctic region, and the amplitude and phase of the eight principal tide constituents in the vertical component are estimated. The results show that GPS is feasible to estimate the OTLD in the polar regions $[14,15]$. The OTLD parameters estimated by GNSS are compared with the results predicted by the ocean tide model, and it is found that there is a systematic deviation between the OTLD parameters estimated by GPS and the ocean tide model predictions, and that the inversion effect of each tide constituent is different [11,16-19]. However, the above studies do not take into account the seasonal variation of OTLD parameters.

The seasonal signal in GNSS observations not only contains the ocean tide signal, but also includes certain other geophysical signals, collectively making periodical variation in station coordinates. Among them, non-tidal ocean loading (NTOL), atmospheric loading (ATL), and hydrological loading (HYDL) are the main contributing sources of mass loading, causing the non-linear motion of the station [20]. By studying the influence of atmosphere, ocean and land water on the coordinate time series of GNSS stations, it is found that the correction of the mass loading can weaken the non-linear motion of most stations [21,22].

This paper aims to study the seasonal variation of OTLD parameters using the moving harmonic analysis (MHA) method based on the kinematic coordinate time series of the direction $\mathrm{U}$ in Hong Kong, and to analyze the influence and contribution of mass loading to the seasonal changes of OTLD parameters. In Section 2, details of the MHA method are presented and the data used in this paper is described. In Section 3, the reliability of the MHA method is verified, and the seasonal variation characteristics of the 6 principal ocean tidal constituents (M2, S2, N2, K1, O1, Q1) are studied by using the MHA method. In Section 4, the influence of mass loading on the seasonal variation of OTLD parameters is discussed. Finally, the conclusion is given in Section 5.

\section{Materials and Methods}

\subsection{Study Region}

The region selected in this paper is Hong Kong, whose geographical distribution is shown in Figure 1. Hong Kong is located in the low latitude coastal area, close to the South China Sea, and the OTL is greatly affected by the change of the offshore ocean tide. The South China Sea is the largest tropical marginal sea in the western Pacific Ocean, with vast waters and complex regions. The central part is a basin with a depth of $6000 \mathrm{~m}$, while the northwest and southwest parts are continental shelves with a depth of less than $100 \mathrm{~m}$ [23].

\subsection{GPS Data}

The GNSS data at 6 stations (HKOH, HKKT, HKST, HKNP, HKMW, and HKSC) in Hong Kong (see Figure 1) were used. GNSS data are released by Système d'Observation du Niveau des Eaux Littorales (SONEL) (http:/ / www.sonel.org). The data span 5 years (2014-2019), and the sampling rate is $30 \mathrm{~s}$. The geographical distribution of stations is shown in Figure 1.

The GNSS data at 6 stations (HKOH, HKKT, HKST, HKNP, HKMW, and HKSC) are processed using the Bernese v5.2 software in kinematic PPP mode, obtaining a solution every $30 \mathrm{~s}$. The hourly solution is obtained by averaging all solutions in an hour. No ocean tidal correction is made in the data processing. The cut-off altitude of the satellite is set to $10^{\circ}$. The tropospheric zenith delay model is the Saastamoinen model [24,25]. Final orbits, satellite clocks, and earth orientation parameters are provided by the Center for Orbit Determination in Europe (CODE) Global Analysis Center. The correction of the solid earth tide and polar tide models are based on the International Earth Rotation and Reference Systems Service (IERS) Conventions 2010 [26]. 


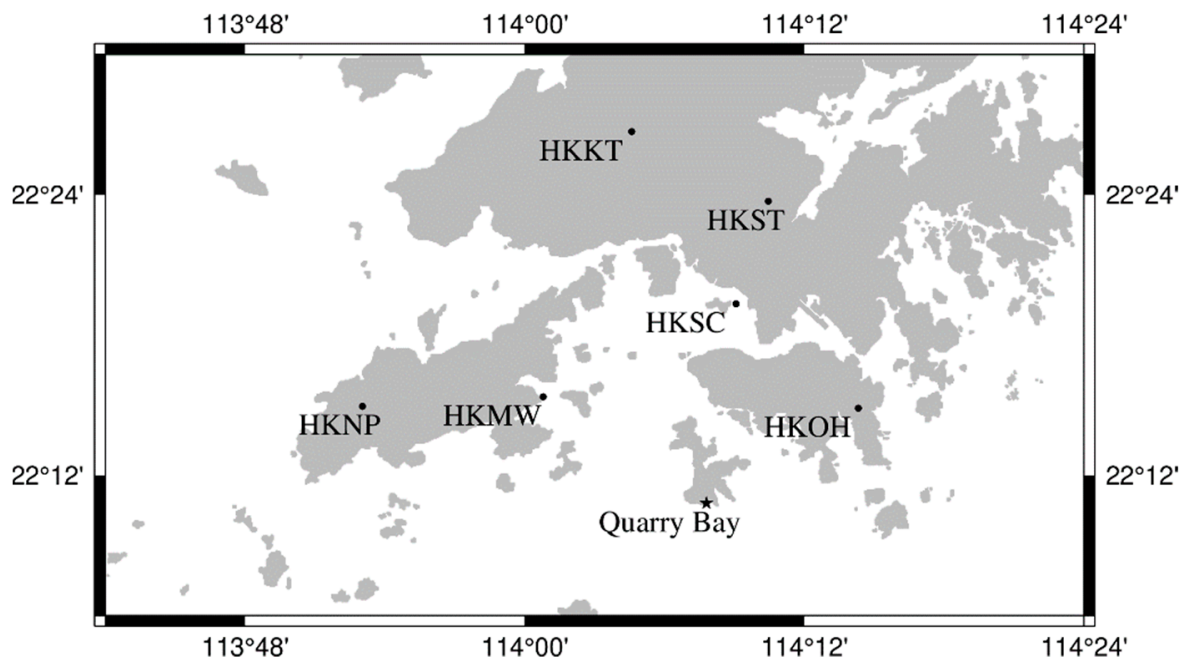

Figure 1. Geographical distribution of Global Navigation Satellite System (GNSS) station (Black spot) and tide gauge station (Black pentagram).

\subsection{Tide Gauge Data}

To verify the reliability of seasonal variation of MHA-derived OTLD parameters, the tide gauge records of Quarry Bay $\left(22.18^{\circ} \mathrm{N}, 114.13^{\circ} \mathrm{E}\right)$ in Hong Kong also are analyzed using MHA. The location of tide gauge station is shown in Figure 1. Hourly sea level data of 2014-2017 at the Quarry Bay tidal gauge station used in this study were obtained from the University of Hawaii Sea Level Center (https:/ / uhslc.soest.hawaii.edu/).

\subsection{Mass Loading Data}

Mass loading considered mainly includes ATL, HYDL, and NTOL. The ATL data are released by the Global Geophysical Fluid Center (GGFC) (http:/ / loading.u-strasbg.fr/ ITRF/). The ATL with a time interval of 3 hours and a grid size of $0.25^{\circ}$ is estimated by using the surface pressure from the operational model of the European Centre for Medium-Range Weather Forecasts (ECMWF). The provisional product of NTOL deformation released by the GeoForschungsZentrum (GFZ) is adopted (http:/ / loading.u-strasbg.fr/ITRF/). The NTOL with a time interval of 12 hours and a grid size of $1^{\circ}$ is derived from non-tidal ocean bottom pressure from the ocean model for circulation and tides (OMCT) [27]. The provisional product of HYDL deformation released by the GFZ (http:/ /rz-vm115.gfz-potsdam.de: 8080 /repository) is also adopted. The HYDL with a time interval of $24 \mathrm{~h}$ and a grid size of $0.5^{\circ}$ are predicted from the global land surface discharge model (LSDM) [28].

\subsection{Moving Harmonic Analysis Method}

In order to obtain higher frequency time-varying signals, observations are divided into monthly segments by calendar month $[7,9,29]$. Moving window is 1 day to form several time periods, and each time period is processed by the CHA method to obtain discrete tidal harmonic parameters (i.e., amplitude and phase lag). This is equivalent to getting a value every day. So, the time resolution of MHA is one day, which is much larger than that of enhanced harmonic analysis (EHA). Therefore, MHA can obtain higher frequency changes. Besides, moving has certain advantage in terms of suppressing non-common signals (noises). The expression of MHA is:

$$
F_{\mathrm{m}}=\left[F_{\mathcal{c}}\left(t_{1} \sim t_{1+30}\right), F_{c}\left(t_{2} \sim t_{2+30}\right), F_{\mathcal{c}}\left(t_{3} \sim t_{3+30}\right), \cdots, F_{c}\left(t_{n-30} \sim t_{n}\right)\right]
$$

where $F_{c}$ are the results of $\mathrm{CHA}, t_{n}$ is $n$th data of time series, and $F_{\mathrm{m}}$ is a set of discrete harmonic constants. 
The MHA method is based on the CHA, so the following is a brief introduction of the CHA method. The time series of coordinate changes in three directions can be expressed as:

$$
y_{i}(t)=b_{0}+b_{1} t+\sum_{k=1}^{M} H_{k} \cos \left(\delta_{k} t+V_{k}\left(t_{0}\right)-\Phi_{k}\right),
$$

where $y_{i}(t)$ is the time series of station coordinates in three directions $(i=N, E, U), k$ is the tidal constituent, and $M$ is the number of ocean tidal constituents. Only 6 principal constituents (M2, S2, N2, O1, K1, Q1) are studied, so $M$ is $6 . t$ is Greenwich time. $H_{k}$ and $\Phi_{k}$ are the amplitude and Greenwich phase lag, respectively. $\delta_{k}$ is the constituent's angular frequency, $\delta_{k}=2 \pi f u_{k}$ in which $f u_{k}$ is the frequency of tidal constituent. $V_{k}$ is the constituent's astronomical argument at reference time $t_{0}$.

\subsection{Enhanced Harmonic Analysis}

The expression of EHA [30] is:

$$
y_{i}(t)=b_{0}+b_{1} t+\sum_{k=1}^{M} H_{k}(t) \cos \left(\delta_{k} t+V_{k}\left(t_{0}\right)-\Phi_{k}(t)\right),
$$

where $H_{k}(t)$ and $\Phi_{k}(t)$ are the function of time. Other variables refer to Equation (2).

Similar to Jin et al. [30] and Pan et al. [31], the independent point scheme and cubic spline interpolation are used to jointly solve the temporally varying harmonic parameters. The independent point scheme is a kind of methodology to connect unresolved parameters in the methodology of harmonic analysis.

\section{Results}

The MHA method is proposed to study the seasonal variation of OTLD parameters in Hong Kong. The results are verified by using CHA and EHA [30,31]. At the same time, fast Fourier transform (FFT) is used to detect the periodic signals in time-varying sequence of amplitude and phase.

The OTLD parameters with a signal-to-noise ratio less than 2 are eliminated in the MHA results, and the values greater than 3 times standard deviation in the OTLD parameter time-varying sequence are eliminated. Finally, SSA interpolate [32,33] is used to fill in missing data.

In addition, because the frequencies of $\mathrm{K} 1$ and $\mathrm{P} 1, \mathrm{~S} 2$ and $\mathrm{K} 2$ is very close, it cannot be clearly separated by using the data of one month $[29,31,34]$. The unresolved constituents P1 and K2 are inferred from K1 and S2, respectively. Those for the inferred constituents are computed using the prescribed amplitude ratios and phase differences [34]. The inference parameters are taken from a yearly harmonic analysis of the 5-year observation data $[29,34]$. The use of an admittance largely eliminates the predictable seasonal variability due to unresolved frequencies (e.g., the effects of P1 and K2 on K1 and S2, respectively) and allows the examination of factors not involving astronomy, such as seasonal climatic variability [9].

\subsection{Analysis of Time-Varying Characteristics of Amplitude}

MHA is used to estimate time-varying OTLD parameters from kinematic coordinate time series. The time-varying results of amplitude are shown in Figures 2-7. 


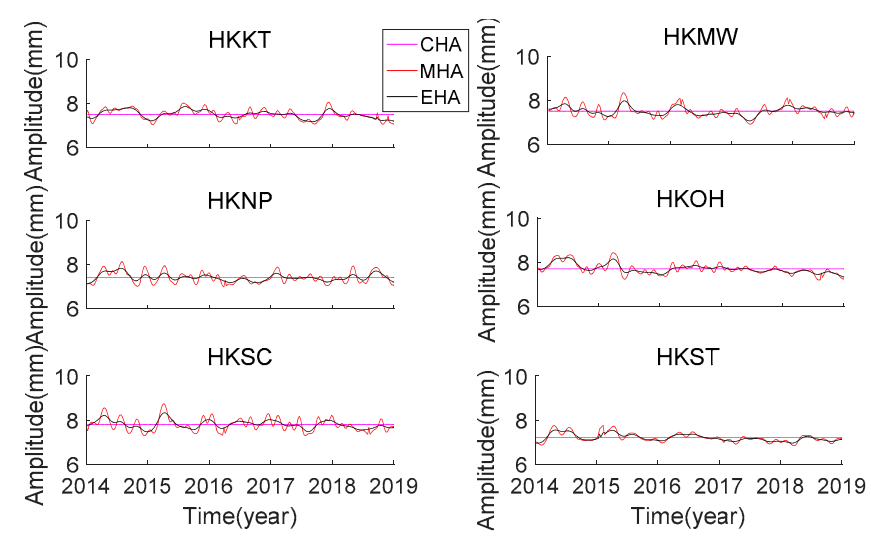

Figure 2. Seasonal variation of the amplitude parameter of $\mathrm{K} 1$ ocean tide loading displacement (OTLD).

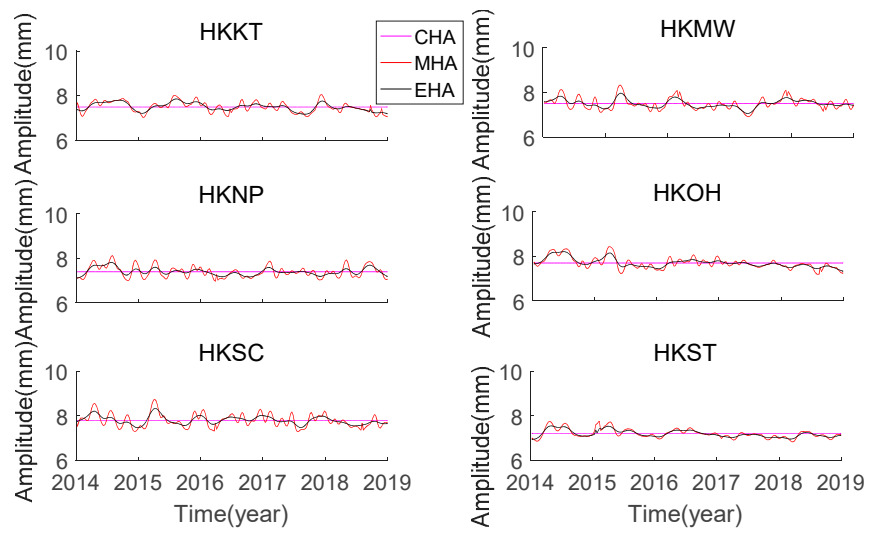

Figure 3. Seasonal variation of the amplitude parameter of O1 OTLD.

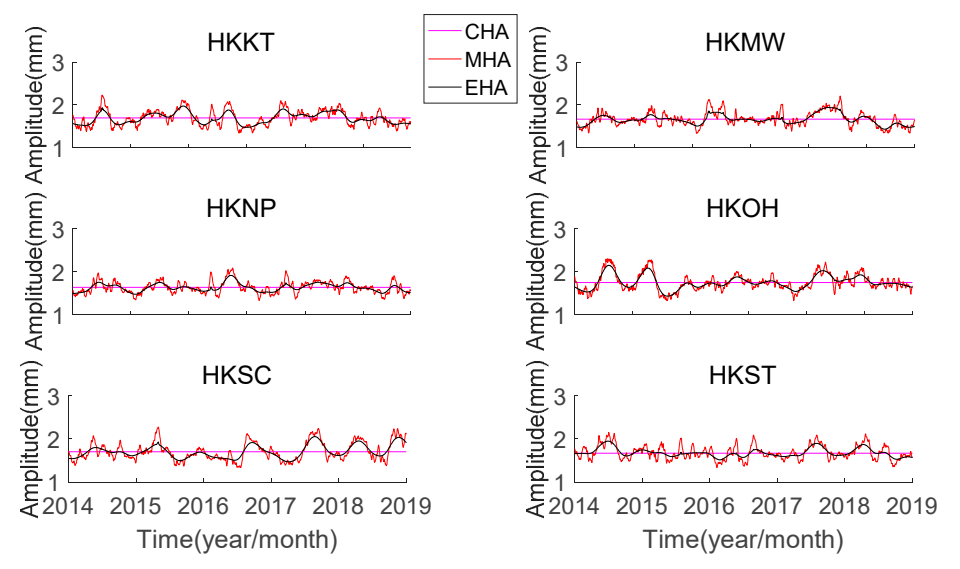

Figure 4. Seasonal variation of the amplitude parameter of Q1 OTLD. 

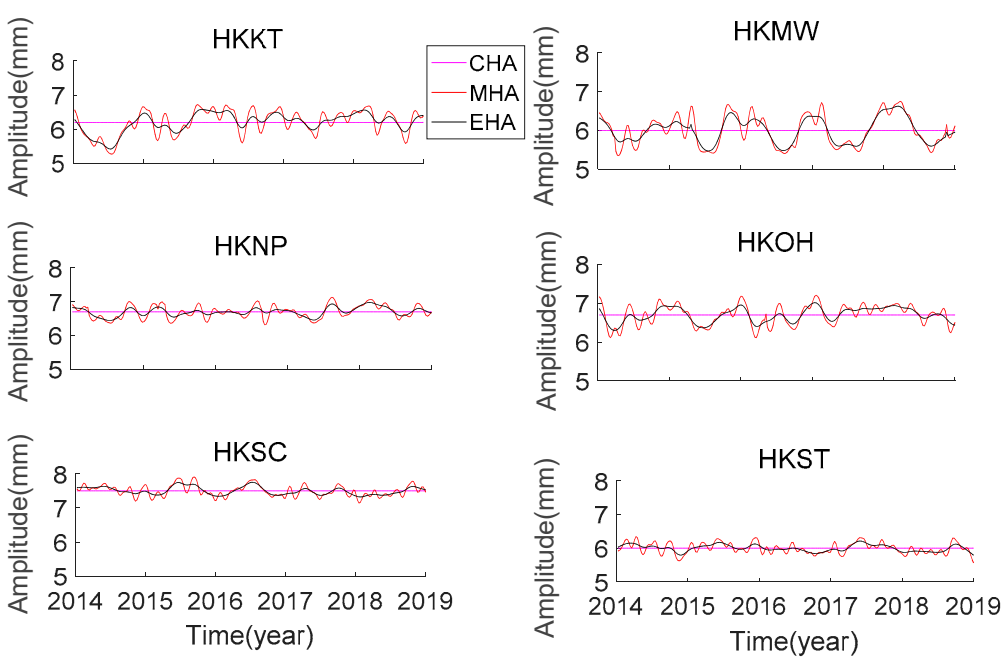

Figure 5. Seasonal variation of the amplitude parameter of M2 OTLD.
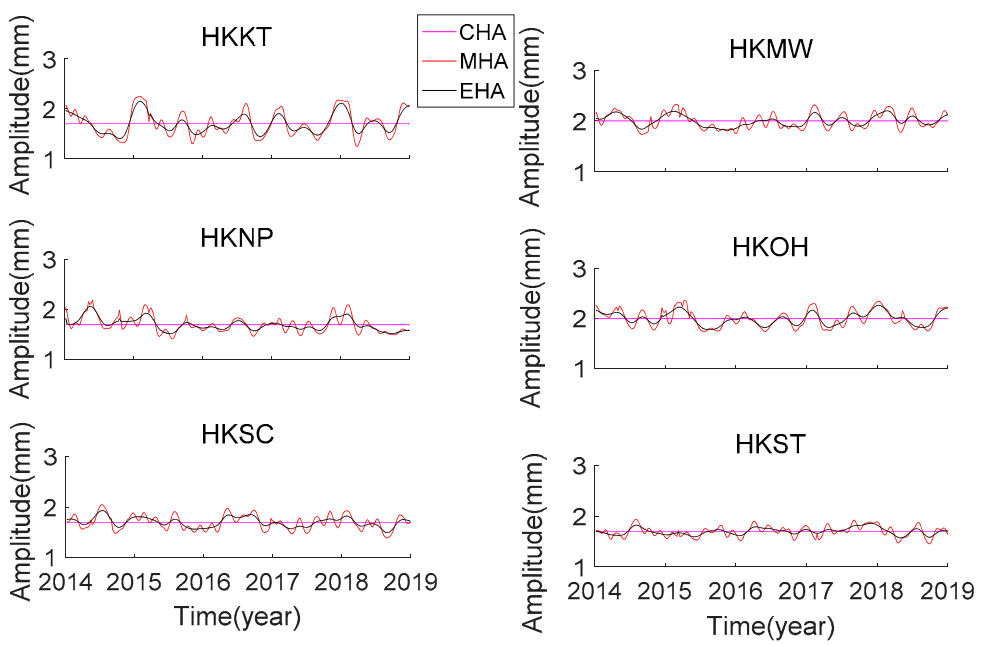

Figure 6. Seasonal variation of the amplitude parameter of S2 OTLD.
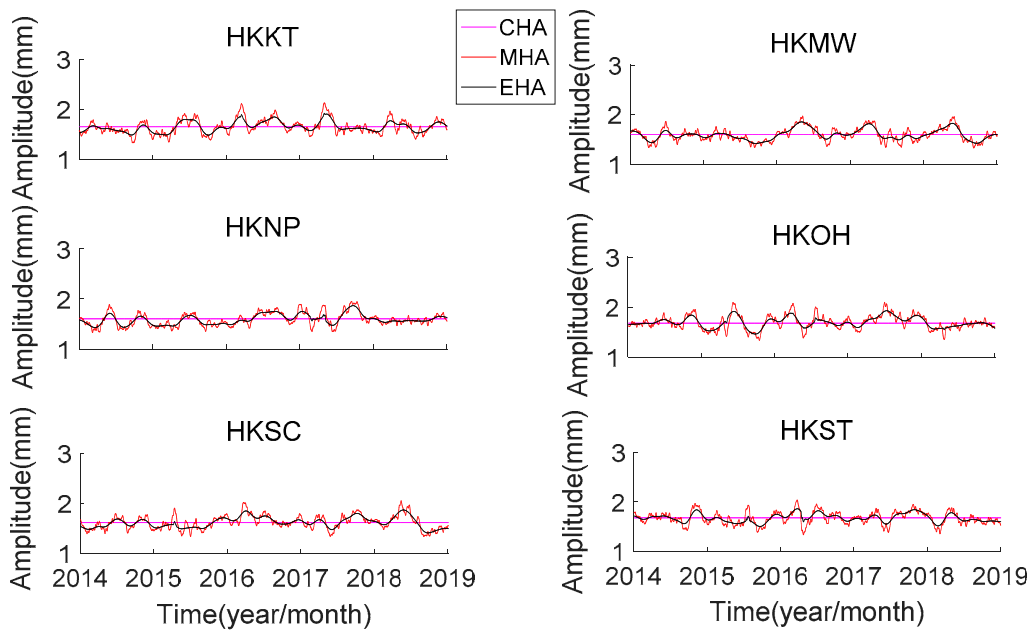

Figure 7. Seasonal variation of the amplitude parameter of N2 OTLD.

From Figures 2-7, it can be seen that the amplitude parameters of the 6 principal tidal constituents in Hong Kong have obvious seasonal variation. The seasonal variation of amplitude by MHA is consistent with that by EHA, and the mean of the estimated results 
of MHA is approximately equal to the estimated results of CHA. This also shows that the use of MHA can effectively estimate the seasonal variation of the harmonic parameters of the principal tidal constituents in Hong Kong. In addition, as shown in Figures 2-7, the MHA method can capture more detailed changes.

The time-varying trend of amplitude parameters of the same tidal constituent at different stations is similar. The amplitude of $\mathrm{K} 1$ at $\mathrm{HKOH}$ and $\mathrm{HKSC}$ has a downward trend. The amplitude relative change of $\mathrm{K} 1$ is about $8.3-11.2 \%$ at Hong Kong. The timevarying trend of amplitude parameters of $\mathrm{O} 1$ at $\mathrm{HKKT}, \mathrm{HKMW}, \mathrm{HKNP}$, and $\mathrm{HKOH}$ is similar. The amplitude relative change of $\mathrm{O} 1$ is about $4-7 \%$ at Hong Kong. The amplitude relative change of Q1 is about 17.6-25.1\%. The oscillation range of the M2 at HKNP is minimum among all the stations. The amplitude relative change of M2 is about $4-8.2 \%$. Mueller et al. [7] and Wang et al. [10] also found changes in the principal harmonics of around $5-10 \%$. The amplitude changes of S2 at each station are similar, and the relative changes are up to $14.7-22.2 \%$. The amplitude relative change of N2 is about $13.8-21.1 \%$.

The FFT is used to analyze the time-varying sequence of OTLD parameters. As the periodic signals contained at each station are relatively similar, only HKKT station is taken as an example for discussion, and the results are shown in Figure 8.
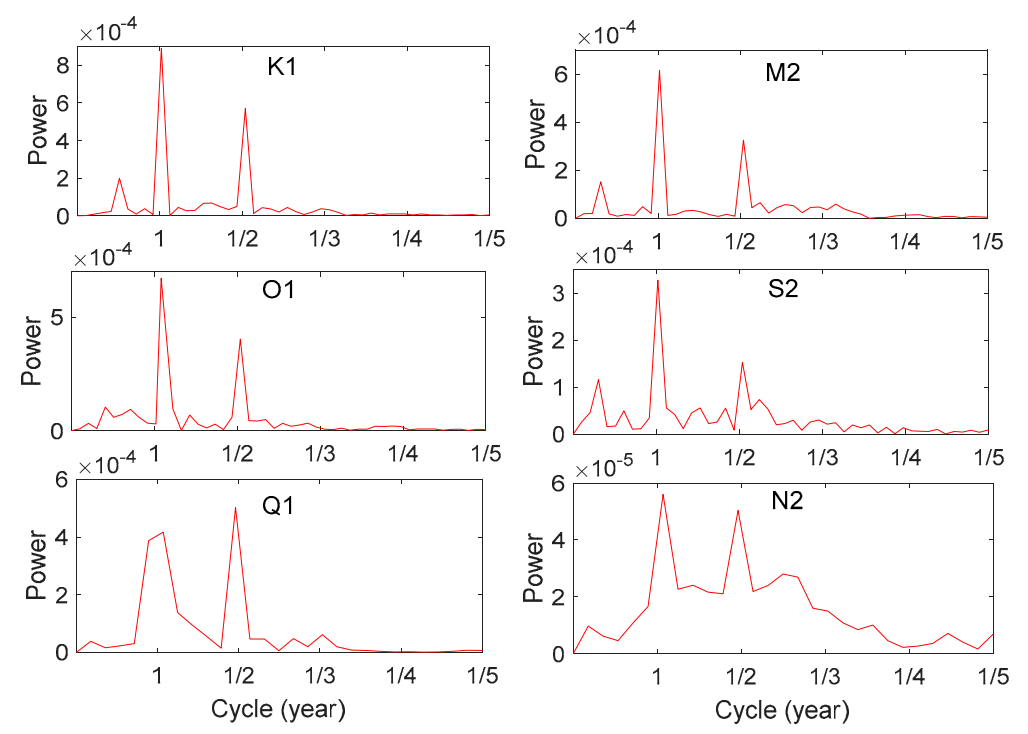

Figure 8. Spectrum analysis of amplitude parameters of 6 principal tidal at HKKT station.

From Figure 8, it can be seen that amplitude parameters of K1, Q1, S2, and N2 have annual signal, the semi-annual signal, and the ter-annual signal, but the power of ter-annual signal is very weak. The power of periodic signals in K1 is the strongest, followed by the power of periodic signals in O1, and the power of periodic signal in N2 is the smallest. This is consistent with the seasonal variation of the amplitude of each tidal constituent. Except Q1, the power of the annual signal of other ocean tide constituents is the largest, followed by the semi-annual signal. The power of ter-annual period of other stations is also very weak by comparing with the annual and semi-annual signals.

\subsection{Analysis of Time-Varying Characteristics of Phase}

The MHA method is used to detect the time-varying signal of the phase parameters. The time-varying results of the phase parameters are listed in Table 1.

It can be seen from Table 1 that the average oscillation ranges of phase parameters of $\mathrm{M} 2, \mathrm{~S} 2, \mathrm{~N} 2, \mathrm{~K} 1, \mathrm{O} 1$, and $\mathrm{Q} 1$ are $9.3^{\circ}, 9.3^{\circ}, 15.9^{\circ}, 13.1^{\circ}, 19.6^{\circ}$, and $18.7^{\circ}$, respectively. It shows that the oscillation range of diurnal tide is larger than that of semidiurnal tide. The time-varying sequence of phase parameters mainly includes annual, semi-annual, and ter-annual periods. The power of ter-annual period is very weak by comparing with the annual and semi-annual signals. 
Table 1. Oscillation range of phase parameters (unit: degree) and the main cycle (unit: year).

\begin{tabular}{cccccccc}
\hline Site & Index & M2 & S2 & N2 & K1 & O1 & Q1 \\
\hline \multirow{2}{*}{ HKKT } & Range & 9.7 & 9.3 & 15.2 & 13.8 & 20.2 & 20.4 \\
& Cycle & $1,1 / 2,1 / 3,1 / 4$ & $1,1 / 2,1 / 3$ & $1,1 / 2$ & $1,1 / 2,1 / 3$ & $1,1 / 2,1 / 3$ & $1,1 / 2,1 / 3$ \\
\hline \multirow{2}{*}{ HKMW } & Range & 9.4 & 9.6 & 15.3 & 12.5 & 19.3 & 21.5 \\
& Cycle & $1,1 / 2,1 / 3$ & $1,1 / 2,1 / 3$ & $1,1 / 2,1 / 3$ & $1,1 / 2,1 / 3$ & $1,1 / 2,1 / 3$ & $1,1 / 2,1 / 3$ \\
\hline \multirow{2}{*}{ HKNP } & Range & 9.6 & 9.4 & 16.9 & 12.8 & 19.9 & 18.6 \\
& Cycle & $1,1 / 2,1 / 3$ & $1,1 / 2,1 / 3$ & $1,1 / 2,1 / 3$ & $1,1 / 2,1 / 3$ & $1,1 / 2,1 / 3$ & $1,1 / 2,1 / 3$ \\
\hline \multirow{2}{*}{ HKOH } & Range & 8.9 & 9.5 & 14.2 & 12.3 & 18.6 & 15.7 \\
& Cycle & $1,1 / 2,1 / 3$ & $1,1 / 2,1 / 3,1 / 4$ & $1,1 / 2,1 / 3$ & $1,1 / 2,1 / 3$ & $1,1 / 2,1 / 3$ & $1,1 / 2$ \\
\hline \multirow{2}{*}{ HKSC } & Range & 9.2 & 8.8 & 16.7 & 13.6 & 20.1 & 17.5 \\
& Cycle & $1,1 / 2,1 / 3$ & $1,1 / 2,1 / 3$ & $1,1 / 2,1 / 3$ & $1,1 / 2,1 / 3$ & $1,1 / 2,1 / 3$ & $1,1 / 2,1 / 3$ \\
\hline \multirow{2}{*}{ HKST } & Range & 9.0 & 9.3 & 17.1 & 14.1 & 19.5 & 18.9 \\
& Cycle & $1,1 / 2,1 / 3$ & $1,1 / 2,1 / 3$ & $1,1 / 2,1 / 3$ & $1,1 / 2,1 / 3$ & $1,1 / 2,1 / 3$ & $1,1 / 2,1 / 3$ \\
\hline
\end{tabular}

It is widely known that the OTL is caused by the redistribution of ocean mass due to ocean tides. Seasonal variations in ocean tides are bound to cause seasonal variation in OTLD. Seasonal variation of sea level changes will cause seasonal variation in ocean tides [35]. Seasonal stratification also has several noticeable effects on the ocean tides [7,10,36,37]. All of these factors will indirectly cause the seasonal variation of OTLD parameters.

\subsection{Accuracy Verification of Moving Harmonic Analysis}

To verify the reliability of MHA, the mean (MEAN), maximum (MAX), minimum (MIN), standard deviation (STD) of root mean squared errors (RMSE) of MHA-derived OTLD parameters over 5 years are counted, and the results are listed in Table 2.

Table 2. Root mean squared error (RMSE) statistics of moving harmonic analysis (MHA)-derived OTLD parameters.

\begin{tabular}{cccccccc}
\hline \multicolumn{2}{c}{$\begin{array}{c}\text { Ocean Tidal } \\
\text { Constituents }\end{array}$} & O1 & K1 & Q1 & M2 & S2 & N2 \\
\hline \multirow{2}{*}{$\begin{array}{c}\text { Amplitude } \\
(\mathrm{mm})\end{array}$} & MAX & 0.81 & 0.79 & 0.56 & 0.80 & 0.68 & 0.48 \\
& MIN & 0.05 & 0.07 & 0.02 & 0.09 & 0.07 & 0.03 \\
& STD & 0.49 & 0.54 & 0.25 & 0.31 & 0.44 & 0.22 \\
Phase $\left(^{\circ}\right)$ & MAX & 5.12 & 0.15 & 0.09 & 0.10 & 0.10 & 0.09 \\
\hline & MIN & 0.75 & 10.25 & $11 . .2$ & 7.24 & 6.25 & 10.24 \\
& STD & 2.33 & 7.15 & 7.14 & 3.49 & 4.41 & 3.21 \\
\hline
\end{tabular}

It can be seen from Table 2 that the mean RMSE of amplitude and phase of K1 is the largest, that of $\mathrm{O} 1$ is the second, and that of N2 is the smallest. The mean RMSE of amplitude and phase of $\mathrm{K} 1$ in direction $\mathrm{U}$ is the largest, reaching $0.54 \mathrm{~mm}$ and $7.15^{\circ}$, respectively. The STD of RMSE of amplitude and phase of K1 in direction $\mathrm{U}$ is the largest, reaching $0.15 \mathrm{~mm}$ and $1.51^{\circ}$, respectively. The mean RMSE of amplitude of N2 is the smallest. The mean RMSE of amplitude of 6 constituents are $0.2-0.5 \mathrm{~mm}$. Those results show that it is feasible to use MHA to study the seasonal variation of OTLD parameters.

To verify the reliability of seasonal variation of MHA-derived OTLD parameters, the tide gauge records of Quarry Bay in Hong Kong also are analyzed using MHA and EHA. The seasonal variation of ocean tides in Hong Kong is shown in Figure 9. From Figure 9, it can be seen that the 6 principal ocean tidal constituents M2, S2, N2, K1, O1, and Q1 in Hong Kong have obvious seasonal changes of annual and semi-annual, which is similar to the seasonal variation of MHA-derived OTLD parameters by GNSS. 

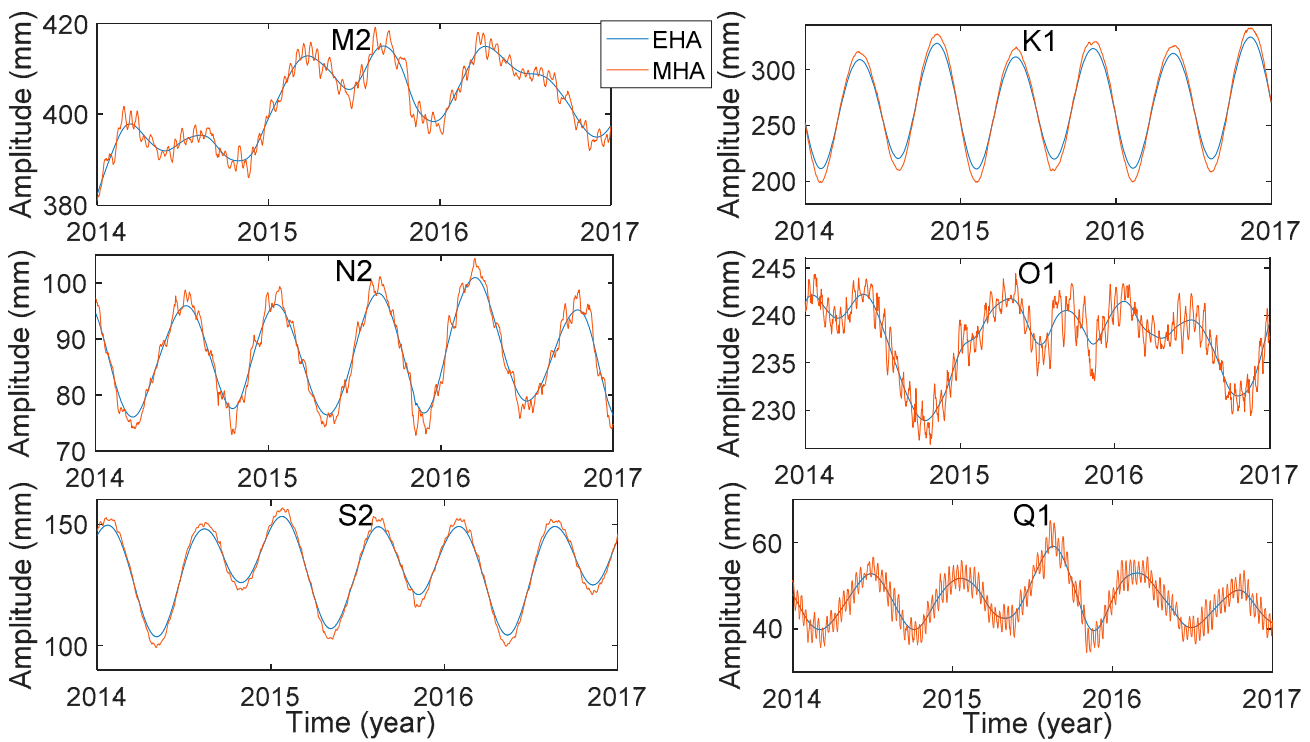

Figure 9. Seasonal variations of amplitude parameters of 6 principal tidal constituents at Quarry Bay.

At the same time, the seasonal variations of the OTLD's amplitude by GNSS and the seasonal variations of the ocean tide's amplitude by tide gauge are statistically and comparatively analyzed. The results are listed in Table 3.

Table 3. The statistics of variation of the amplitude parameter by GNSS and tide gauge.

\begin{tabular}{ccc}
\hline Tidal Constituents & $\begin{array}{c}\text { Variation of the OTLD's } \\
\text { Amplitude by GNSS }\end{array}$ & $\begin{array}{c}\text { Variation of the Ocean Tide's } \\
\text { Amplitude by Tide Gauge }\end{array}$ \\
\hline K1 & About $8.3-11.2 \%$ & About $26.0 \%$ \\
O1 & About $4-6.3 \%$ & About $6.3 \%$ \\
Q1 & About $17.6-25.1 \%$ & About $26.3 \%$ \\
M2 & About $4-8.2 \%$ & About $4.8-5.1 \%$ \\
N2 & About $13.8-21.2 \%$ & About $22.2 \%$ \\
S2 & About $14.7-22.2 \%$ & About $20.8 \%$ \\
\hline
\end{tabular}

It can be seen from the statistical results in Table 3 that the seasonal variations of OTLD parameters of $\mathrm{M} 2, \mathrm{~S} 2, \mathrm{~N} 2, \mathrm{~K} 1, \mathrm{Q} 1$, and $\mathrm{O} 1$ estimated by GNSS are about $4-8.2 \%, 14.7-22.2 \%$, $13.8-21.2 \%, 8.3-11.2 \%, 17.6-25.1 \%$, and $4-6.3 \%$, respectively. The seasonal variations of ocean tide parameters of $\mathrm{M} 2, \mathrm{~S} 2, \mathrm{~N} 2, \mathrm{~K} 1, \mathrm{Q} 1$, and $\mathrm{O} 1$ estimated by tide gauge are about $4.8-5.1 \%, 20.8 \%, 22.2 \%, 26 \%, 26.3 \%$, and $6.25 \%$, respectively. The seasonal variations of OTLD parameters of M2, S2, N2, Q1, and O1 constituents base on GNSS and the seasonal variations of ocean tide parameters of $\mathrm{M} 2, \mathrm{~S} 2, \mathrm{~N} 2, \mathrm{Q} 1$, and $\mathrm{O} 1$ constituents base on tide gauge station are very similar. The seasonal variation of OTLD parameter of K1 base on GNSS is slightly smaller than the seasonal variation of ocean tide parameter of K1 base on tide gauge. The GPS satellite orbit errors and multipath effects related to the two periods result in large uncertainties of K1 OTLD estimates $[14,38]$. So, the GPS satellite orbit errors and multipath effects may be the two of reasons of the difference between the seasonal variation of OTLD parameter of K1 base on GNSS and those of K1 base on tide gauge.

MHA is developed on the basis of segmented harmonic analysis. Segmented harmonic analysis has been widely used in the study of seasonal variation of ocean tides, and its reliability has been verified $[7,9,29]$. Besides, the mean of the estimated results of MHA is approximately equal to the estimated results of $\mathrm{CHA}$. All of the above indicates that the MHA method is reliable. 


\section{Discussion}

Although GNSS technique has many advantages in studying OTLD, it is also affected by many other geophysical factors, such as mass loading including NTOL, ATL, and HYDL, which may be mixed with ocean tidal signals in time series [39].

In order to study the influence of mass loading on the seasonal variation of OTLD parameters, the seasonal variations of OTLD parameters with/without mass loading correction are studied. The difference of the seasonal variation sequence of amplitude parameters with/without the mass loading correction is analyzed, and the results are listed in Tables 4-6.

Table 4. Difference of seasonal variation sequence of amplitude parameter with/without hydrological loading (HYDL) correction (mm).

\begin{tabular}{|c|c|c|c|c|c|c|c|}
\hline \multicolumn{2}{|c|}{$\begin{array}{l}\text { Ocean Tidal } \\
\text { Constituents }\end{array}$} & \multirow{2}{*}{$\begin{array}{c}\text { M2 } \\
0.4\end{array}$} & \multirow{2}{*}{$\begin{array}{l}\mathbf{S} 2 \\
0.3\end{array}$} & \multirow{2}{*}{$\begin{array}{l}\mathbf{N} 2 \\
0.3\end{array}$} & \multirow{2}{*}{$\begin{array}{c}\mathbf{K 1} \\
0.1\end{array}$} & \multirow{2}{*}{$\begin{array}{l}\text { O1 } \\
0.5\end{array}$} & \multirow{2}{*}{$\begin{array}{c}\text { Q1 } \\
0.4\end{array}$} \\
\hline \multirow{4}{*}{ HKKT } & MAX & & & & & & \\
\hline & MIN & -1.2 & -3.8 & -2.4 & -1.6 & -0.8 & -1.8 \\
\hline & MEAN & -0.1 & -0.4 & -0.5 & -0.3 & -0.1 & -0.3 \\
\hline & STD & 0.3 & 0.2 & 0.2 & 0.3 & 0.1 & 0.2 \\
\hline \multirow{4}{*}{ HKMW } & MAX & 1.0 & 5.0 & 2.2 & 1.3 & 0.8 & 0.7 \\
\hline & MIN & -1.6 & -1.5 & -0.9 & -1.4 & -0.9 & -1.0 \\
\hline & MEAN & -0.2 & 0.1 & 0.2 & -0.2 & -0.1 & -0.1 \\
\hline & STD & 0.4 & 0.3 & 0.4 & 0.3 & 0.1 & 0.3 \\
\hline \multirow{4}{*}{ HKNP } & MAX & 5.2 & 7.2 & 2.6 & 4.7 & 3.4 & 1.5 \\
\hline & MIN & -1.1 & -1.7 & -1.1 & -1.1 & -0.3 & -1.1 \\
\hline & MEAN & 0.2 & 0.4 & 0.4 & 0.1 & 0.6 & 0.4 \\
\hline & STD & 0.3 & 0.5 & 0.4 & 0.7 & 1.01 & 0.5 \\
\hline \multirow{4}{*}{$\mathrm{HKOH}$} & MAX & 0.7 & 0.2 & 0.6 & 0.5 & 0.4 & 0.3 \\
\hline & MIN & -1.6 & -2.0 & -1.2 & -0.7 & -0.9 & -0.7 \\
\hline & MEAN & -0.3 & -0.5 & -0.4 & -0.1 & -0.2 & -0.2 \\
\hline & STD & 0.3 & 0.3 & 0.2 & 0.3 & 0.1 & 0.2 \\
\hline \multirow{4}{*}{ HKSC } & MAX & 6.2 & 8.1 & 2.5 & 5.2 & 3.3 & 1.7 \\
\hline & MIN & -1.3 & -2.5 & -1.8 & -1.6 & -1.3 & -1.0 \\
\hline & MEAN & 1.1 & 1.3 & 0.6 & 1.2 & 0.4 & 0.4 \\
\hline & STD & 2.0 & 2.4 & 0.9 & 2.2 & 1.0 & 0.6 \\
\hline \multirow{4}{*}{ HKST } & MAX & 0.8 & 2.7 & 0.7 & 0.4 & 1.4 & 0.8 \\
\hline & MIN & -1.5 & -2.3 & -0.9 & -1.3 & -1.1 & -1.2 \\
\hline & MEAN & -0.3 & -0.3 & 0.2 & -0.2 & 0.1 & -0.3 \\
\hline & STD & 0.2 & 0.6 & 0.1 & 0.2 & 0.3 & 0.2 \\
\hline
\end{tabular}

As is listed in Table 4, the seasonal variation of OTLD parameters after HYDL correction does not change significantly. Except for HKSC, the mean and standard deviations of the difference of the seasonal variation with/without the HYDL correction are around $0 \mathrm{~mm}$ at most stations. This shows that the HYDL has little influence on the seasonal variation of OTLD parameters. HYDL is mainly caused by surface water, groundwater, and snow cover. The main periodic signals are annual and semi-annual signals [40,41]. Therefore, it is reasonable that HYDL has little influence on seasonal change of OTLD parameters. The kinematic GPS coordinate time series at HKSC station was checked. The STD of HKSC station time series is about 2.2 times of those of other stations, reaching 0.026 $\mathrm{m}$. Therefore, we think that the accuracy of the coordinate time series of HKSC station is lower than that of other stations. We think that this may be one of the reasons for the abnormality of HKSC station. 
Table 5. Difference of seasonal change sequence of amplitude parameter with/without atmospheric loading (ATL) correction (mm).

\begin{tabular}{|c|c|c|c|c|c|c|c|}
\hline \multicolumn{2}{|c|}{$\begin{array}{l}\text { Ocean Tidal } \\
\text { Constituents }\end{array}$} & M2 & S2 & N2 & K1 & 01 & Q1 \\
\hline \multirow{4}{*}{ HKKT } & MAX & 0.6 & 0.2 & 0.4 & 0.1 & 1.1 & 0.6 \\
\hline & MIN & -2.4 & -3.2 & -2.8 & -2.4 & -0.9 & -1.5 \\
\hline & MEAN & -1.1 & -1.4 & -1.5 & -1.2 & 0.7 & -0.8 \\
\hline & STD & 1.1 & 1.2 & 1.2 & 1.2 & 0.6 & 0.9 \\
\hline \multirow{4}{*}{ HKMW } & MAX & 1.3 & 5.4 & 2.6 & 1.5 & 0.6 & 1.2 \\
\hline & MIN & -2.2 & -2.3 & -2.5 & -1.5 & -1.3 & -1.6 \\
\hline & MEAN & -1.1 & -1.2 & -0.8 & -0.9 & -0.7 & -1.1 \\
\hline & STD & 1.0 & 1.3 & 1.4 & 1.2 & 0.6 & 1.1 \\
\hline \multirow{4}{*}{ HKNP } & MAX & 5.5 & 7.4 & 5.6 & 4.5 & 3.5 & 3.4 \\
\hline & MIN & -2.3 & -2.2 & -1.8 & -2.4 & -0.8 & -1.5 \\
\hline & MEAN & 1.2 & 1.3 & 1.2 & 1.3 & 0.6 & 1.7 \\
\hline & STD & 2.3 & 2.2 & 1.9 & 1.6 & 1.2 & 1.1 \\
\hline \multirow{4}{*}{$\mathrm{HKOH}$} & MAX & 0.6 & 0.4 & 1.0 & 0.5 & 0.7 & 1.2 \\
\hline & MIN & -1.8 & -2.4 & -2.5 & -1.7 & -0.9 & -1.1 \\
\hline & MEAN & -1.1 & -1.3 & -1.4 & -1.1 & 0.1 & 0.6 \\
\hline & STD & 1.0 & 1.1 & 1.3 & 0.8 & 0.4 & 0.9 \\
\hline \multirow{4}{*}{ HKSC } & MAX & 6.7 & 8.4 & 7.5 & 5.7 & 3.0 & 4.8 \\
\hline & MIN & -1.4 & -2.7 & -3.2 & -1.3 & -1.1 & -0.9 \\
\hline & MEAN & 1.3 & 1.6 & 2.4 & 1.1 & 0.5 & 2.0 \\
\hline & STD & 2.2 & 2.8 & 2.3 & 2.0 & 1.1 & 1.3 \\
\hline \multirow{4}{*}{ HKST } & MAX & 0.7 & 2.9 & 1.9 & 0.3 & 1.4 & 2.0 \\
\hline & MIN & -2.1 & -2.5 & -2.6 & -2.0 & -1.2 & -1.6 \\
\hline & MEAN & -1.4 & -1.4 & -1.3 & -1.1 & 0.8 & 0.8 \\
\hline & STD & 1.2 & 1.1 & 1.3 & 1.0 & 0.9 & 0.7 \\
\hline
\end{tabular}

The mean differences of seasonal variation of the amplitude parameters with/without the ATL correction have absolute values in the range 0.1-2.4 $\mathrm{mm}$. The standard deviations of the difference of the seasonal variation of the amplitude parameters with/without the ATL correction are $0.4-2.0 \mathrm{~mm}$ at most stations. The standard deviation's means of difference for $\mathrm{M} 2, \mathrm{~S} 2, \mathrm{~N} 2, \mathrm{~K} 1, \mathrm{O} 1$, and $\mathrm{Q} 1$ at six stations are 1.5, 1.6, 1.6, 1.3, 0.8, and $1.0 \mathrm{~mm}$, respectively. This shows that the ATL has certain influence on the seasonal change of OTLD parameters. Many studies have found that there are obvious diurnal and semi-diurnal signals of ATL $[42,43]$. These signals may be mixed with ocean tide signals, which have certain impact on the seasonal changes of OTLD parameters. Devlin et al. [9] analyzed the water level time series from 20 tide gauges in Southeast Asia and the results shown that diurnal and semidiurnal astronomical tides exhibit strong seasonal variability of both amplitude and phase. It is found that the tidal properties are coherent with the western North Pacific monsoon index, indicating that monsoonal mechanisms are the cause. Monsoon circulation is an important part of atmospheric circulation.

It can be concluded from Table 6 that the means of the standard deviation of the difference for M2, S2, N2, K1, O1, and Q1 at each station after NTOL correction are 0.43 , $0.46,0.53,0.50,0.51$, and $0.60 \mathrm{~mm}$, respectively. The mean difference for M2, S2, N2, K1, O1, and Q1 at each station is almost less than $0.5 \mathrm{~mm}$. Therefore, the seasonal variation of OTLD parameters at each station has not changed significantly after the NTOL correction. NTOL is caused by a redistribution of the ocean's internal mass that is driven by atmospheric circulation, a change in the mass entering or leaving the ocean, and/or a change in the integrated atmospheric mass over the ocean areas, with a main periodic signal of annual signal $[44,45]$. This may be the reason why it has little effect on the seasonal variation of OTLD parameters. 
Table 6. Difference of seasonal change sequence of amplitude parameter with/without non-tidal ocean loading (NTOL) correction (mm).

\begin{tabular}{|c|c|c|c|c|c|c|c|}
\hline \multicolumn{2}{|c|}{$\begin{array}{l}\text { Ocean Tidal } \\
\text { Constituents }\end{array}$} & M2 & S2 & N2 & K1 & 01 & Q1 \\
\hline \multirow{4}{*}{ HKKT } & MAX & 1.5 & 2.5 & 1.6 & 1.5 & 3.5 & 2.8 \\
\hline & MIN & -1.7 & -3.2 & -1.7 & -1.4 & -2.2 & -2.5 \\
\hline & MEAN & -0.2 & -0.4 & -0.3 & -0.2 & -0.1 & 0.2 \\
\hline & STD & 0.5 & 0.2 & 0.3 & 0.4 & 0.7 & 0.5 \\
\hline \multirow{4}{*}{ HKMW } & MAX & 1.6 & 6.1 & 0.9 & 1.1 & 3.0 & 3.4 \\
\hline & MIN & -2.7 & -4.1 & -1.6 & -3.2 & -2.4 & -2.5 \\
\hline & MEAN & -0.2 & 0.1 & -0.5 & -0.2 & -0.2 & 0.4 \\
\hline & STD & 0.5 & 0.6 & 0.6 & 0.6 & 0.7 & 0.8 \\
\hline \multirow{4}{*}{ HKNP } & MAX & 5.2 & 7.5 & 4.2 & 4.6 & 3.9 & 3.8 \\
\hline & MIN & -1.4 & -2.1 & -2.1 & -1.5 & -1.6 & -1.5 \\
\hline & MEAN & 0.2 & 0.8 & 0.9 & 0.3 & 0.6 & 0.9 \\
\hline & STD & 0.2 & 0.7 & 0.8 & 0.9 & 0.3 & 0.6 \\
\hline \multirow{4}{*}{$\mathrm{HKOH}$} & MAX & 2.5 & 3.5 & 1.9 & 1.3 & 2.4 & 2.7 \\
\hline & MIN & -2.1 & -3.7 & -2.1 & -1.1 & -2.5 & -2.6 \\
\hline & MEAN & -0.2 & -0.5 & -0.3 & -0.3 & 0.1 & 0.3 \\
\hline & STD & 0.6 & 0.1 & 0.5 & 0.5 & 0.7 & 0.6 \\
\hline \multirow{4}{*}{ HKSC } & MAX & 6.6 & 8.3 & 4.2 & 5.5 & 4.2 & 3.9 \\
\hline & MIN & -1.7 & -2.7 & -3.8 & -1.6 & -2.5 & -2.6 \\
\hline & MEAN & 1.6 & 0.5 & 0.3 & 0.3 & 0.6 & 0.4 \\
\hline & STD & 0.3 & 0.1 & 0.3 & 0.1 & 0.2 & 0.5 \\
\hline \multirow{4}{*}{ HKST } & MAX & 1.6 & 3.7 & 2.2 & 1.7 & 2.6 & 2.1 \\
\hline & MIN & -2.4 & -3.5 & -3.2 & -1.4 & -2.5 & -2.6 \\
\hline & MEAN & -0.1 & -0.3 & -0.5 & 0 & 0 & -0.1 \\
\hline & STD & 0.5 & 1.1 & 0.7 & 0.5 & 0.5 & 0.6 \\
\hline
\end{tabular}

At the same time, the contribution of mass loading to the seasonal variation of the OTLD parameter is analyzed. The results are shown in Table 7. The formula [20] is:

$$
\text { Contribution }=1-\left(A_{2} / A_{1}\right)^{2}
$$

where $A_{2}$ and $A_{1}$ are the average amplitudes of the series with/without mass loading correction, respectively. Contribution can also be called power explained.

It can be seen from Table 7 that ATL has some contribution to the seasonal variation of the OTLD parameter. The average contributions of the ATL to the seasonal variation of 6 principle tide constituents' OTLD parameters are $9.01 \%, 6.77 \%, 5.20 \%, 6.20 \%, 5.55 \%$, and $3.22 \%$, respectively. The average contributions of HYDL to the seasonal variation of 6 principal tidal constituents' OTLD parameters are $0.33 \%, 0.35 \%, 0.25 \%, 0.60 \%, 0.43 \%$, and $0.25 \%$, respectively. The average contributions of NTOL to the seasonal variation of 6 principal tidal constituents' OTLD parameters are $0.87 \%, 0.71 \%, 0.60 \%, 0.72 \%, 0.71 \%$, and $0.47 \%$, respectively. NTOL and HYDL contribute very little to the seasonal variation of OTLD parameters and can be ignored. 
Table 7. Contribution rate of the mass loading at each station to the seasonal variation of OTLD parameter.

\begin{tabular}{|c|c|c|c|c|c|c|c|}
\hline Correction & Site & M2 & $\mathrm{S} 2$ & N2 & K1 & O1 & Q1 \\
\hline \multirow{6}{*}{ ATL } & HKKT & $9.17 \%$ & $12.74 \%$ & $5.21 \%$ & $7.54 \%$ & $4.04 \%$ & $4.31 \%$ \\
\hline & HKMW & $11.05 \%$ & $4.79 \%$ & $4.24 \%$ & $5.54 \%$ & $5.62 \%$ & $3.24 \%$ \\
\hline & HKNP & $10.11 \%$ & $5.13 \%$ & $6.16 \%$ & $10 . .17 \%$ & $9.14 \%$ & $3.99 \%$ \\
\hline & $\mathrm{HKOH}$ & $9.40 \%$ & $10 . .01 \%$ & $5.67 \%$ & $5.01 \%$ & $2.96 \%$ & $2.10 \%$ \\
\hline & HKSC & $7.46 \%$ & $3.95 \%$ & $4.09 \%$ & $6.72 \%$ & $4.68 \%$ & $2.07 \%$ \\
\hline & HKST & $6.87 \%$ & $7.26 \%$ & $5.81 \%$ & $6.18 \%$ & $6.85 \%$ & $3.61 \%$ \\
\hline \multirow{6}{*}{ HYDL } & HKKT & $0.43 \%$ & $0.16 \%$ & $0.09 \%$ & $0.57 \%$ & $0.84 \%$ & $0.12 \%$ \\
\hline & HKMW & $0.06 \%$ & $0.21 \%$ & $0.11 \%$ & $0.61 \%$ & $0.75 \%$ & $0.09 \%$ \\
\hline & HKNP & $0.29 \%$ & $0.69 \%$ & $0.41 \%$ & $0.34 \%$ & $0.23 \%$ & $0.47 \%$ \\
\hline & $\mathrm{HKOH}$ & $0.58 \%$ & $0.03 \%$ & $0.08 \%$ & $0.18 \%$ & $0.40 \%$ & $0.29 \%$ \\
\hline & HKSC & $0.29 \%$ & $0.64 \%$ & $0.54 \%$ & $0.21 \%$ & $0.26 \%$ & $0.34 \%$ \\
\hline & HKST & $0.34 \%$ & $0.37 \%$ & $0.24 \%$ & $1.69 \%$ & $0.11 \%$ & $0.18 \%$ \\
\hline \multirow{6}{*}{ NTOL } & HKKT & $0.96 \%$ & $0.35 \%$ & $0.34 \%$ & $1.01 \%$ & $0.67 \%$ & $0.38 \%$ \\
\hline & HKMW & $0.27 \%$ & $1.01 \%$ & $0.71 \%$ & $0.64 \%$ & $0.61 \%$ & $0.51 \%$ \\
\hline & HKNP & $1.30 \%$ & $0.62 \%$ & $0.59 \%$ & $0.94 \%$ & $0.54 \%$ & $0.49 \%$ \\
\hline & $\mathrm{HKOH}$ & $1.04 \%$ & $0.85 \%$ & $0.61 \%$ & $0.54 \%$ & $0.41 \%$ & $0.24 \%$ \\
\hline & HKSC & $0.78 \%$ & $0.71 \%$ & $0.54 \%$ & $0.69 \%$ & $1.14 \%$ & $0.62 \%$ \\
\hline & HKST & $0.89 \%$ & $0.69 \%$ & $0.83 \%$ & $0.51 \%$ & $0.87 \%$ & $0.58 \%$ \\
\hline
\end{tabular}

\section{Conclusions}

Based on 5 years of kinematic coordinate time series in direction U of six GNSS stations in Hong Kong, the MHA method is proposed to explore the seasonal variation of the OTLD parameters of the 6 principal tidal constituents (M2, S2, N2, K1, O1, Q1). Additionally, the influence of mass loading on the seasonal variation of OTLD parameters is analyzed. The results show that the MHA method can effectively detect the seasonal variation of OTLD parameters, of which the annual periodic signal, semi-annual periodic signal, and terannual periodic signal are the most obvious. The OTLD's amplitude parameters changes of the 6 principal tidal constituents are around $4 \%-25.1 \%$ and the oscillation ranges of OTLD's phase parameters vary from $8.8^{\circ}$ to $20.2^{\circ}$. ATL has certain influence on the seasonal variation of OTLD parameters. The influence of HYDL and NTOL on the seasonal variation of OTLD parameters is very little and can be ignored.

Author Contributions: J.G., M.Z. and X.L. designed the research. M.Z., X.J. and X.L. developed the algorithm. J.Y., Y.N. and H.G. analyzed data. M.Z. wrote the manuscript with the contributions from J.G. All authors were involved in discussions throughout the development. All authors have read and agreed to the published version of the manuscript.

Funding: This work is supported by the National Natural Science Foundation of China (grant Nos. 41774001, 41374009), the SDUST Research Fund (grant No. 2014TDJH101), State Key Laboratory of Tropical Oceanography, South China Institute of Oceanology, Chinese Academy of Sciences (Project No. LTO2017), and Shandong Province Youth Innovation and Technology Program (Project No. 2019KJN009).

Institutional Review Board Statement: Not applicable.

Informed Consent Statement: Not applicable.

Data Availability Statement: Publicly available datasets were analyzed in this study. The GNSS data can be found here: http://www.sonel.org. The mass loading data can be found here: http: / / loading.u-strasbg.fr/ITRF/ and http:/ /rz-vm115.gfz-potsdam.de:8080/repository. The tide gauge data can be found here: https://uhslc.soest.hawaii.edu/.

Acknowledgments: We are very grateful to the SONEL for providing the GNSS data, and GGFC and GFZ for providing mass loading data. Thanks to Haidong Pan of Ocean University of China for his EHA program. This work is supported by the National Natural Science Foundation of China (grant Nos. 41774001), the SDUST Research Fund (grant No. 2014TDJH101), State Key Laboratory of 
Tropical Oceanography, South China Institute of Oceanology, Chinese Academy of Sciences (Project No. LTO2017) and Shandong Province Youth Innovation and Technology Program (Project No. 2019KJN009).

Conflicts of Interest: The authors declare no conflict of interest.

\section{References}

1. Dragert, H.; James, T.; Lambert, A. Ocean loading corrections for continuous GPS: A case study at the Canadian coastal site Holberg. Geophys. Res. Lett. 2000, 27, 2045-2048. [CrossRef]

2. Zhao, H.; Zhang, Q.; Tu, R.; Liu, Z. Determination of ocean tide loading displacement by GPS PPP with priori information constraint of NAO99b global ocean tide model. Mar. Geod. 2018, 41, 159-176. [CrossRef]

3. Farrell, W. Deformation of the Earth by surface loads. Rev. Geophys. 1972, 10, 761-797. [CrossRef]

4. Thomas, I.; King, M.; Clarke, P. A comparison of GPS, VLBI and model estimates of ocean tide loading displacements. J. Geod. 2007, 81, 359-368. [CrossRef]

5. Yun, H.; Lee, D.; Song, D. Determination of vertical displacements over the coastal area of Korea due to the ocean tide loading using GPS observations. J. Geodyn. 2007, 43, 528-541. [CrossRef]

6. Lei, M.; Wang, Q.; Liu, X.; Xu, B.; Zhang, H. Influence of ocean tidal loading on InSAR offshore areas deformation monitoring. Geod. Geodyn. 2017, 8, 70-76. [CrossRef]

7. Müller, M.; Cherniawsky, J.; Foreman, M.; von Storch, J. Seasonal variation of the M2 tide. Ocean Dyn. 2014, 64, 159-177. [CrossRef]

8. Guo, Z.; Pan, H.; Cao, A.; Lv, X. A harmonic analysis method adapted to capturing slow variations of tidal amplitudes and phases. Cont. Shelf Res. 2018, 164, 37-44. [CrossRef]

9. Devlin, A.; Zaron, E.; Jay, D.; Talke, S.; Pan, J. Seasonality of tides in Southeast Asian waters. J. Phys. Oceanogr. 2018, 48, 1169-1190. [CrossRef]

10. Wang, D.; Pan, H.; Jin, G.; Lv, X. Seasonal variation of the principal tidal constituents in the Bohai Sea. Ocean Sci. 2020, 16, 1-14. [CrossRef]

11. Yuan, L.; Ding, X.; Sun, H.; Zhong, P.; Chen, W. Determination of ocean tide loading displacements in Hong Kong using GPS technique. Sci. China Earth Sci. 2010, 53, 993-1007. [CrossRef]

12. King, M.; Watson, C.; Penna, N.; Clarke, P. Subdaily signals in GPS observations and their effect at semiannual and annual periods. Geophys. Res. Lett. 2008, 35, L03302. [CrossRef]

13. Penna, N.; Clarke, P.; Bos, M.; Baker, T. Ocean tide loading displacements in western Europe: Part 1. Validation of kinematic GPS estimates. J. Geophys. Res. 2015, 120, 6523-6539. [CrossRef]

14. King, M. Kinematic and static GPS techniques for estimating tidal displacements with application to Antarctica. J. Geodyn. 2006, 41,77-86. [CrossRef]

15. Zhang, X.; Andersen, O. Surface ice flow velocity and tide retrieval of the Amery Ice Shelf using Precise Point Positioning. J. Geod. 2006, 80, 171-176. [CrossRef]

16. Schenewerk, M.; Marshall, J.; Dillinger, W. Vertical ocean-loading deformations derived from a global GPS network. J. Geod. Soc. Jpn. 2001, 47, 237-242. [CrossRef]

17. Allinson, C.; Clarke, P.; Edwards, S.; King, M.; Baker, T.; Cruddace, P. Stability of direct GPS estimates of ocean tide loading. Geophys. Res. Lett. 2004, 31, L15603. [CrossRef]

18. Vergnolle, M.; Bouin, M.; Morel, L.; Masson, F.; Durand, S.; Nicolas, J.; Melachroinos, S. GPS estimates of ocean tide loading in NW-France: Determination of ocean tide loading constituents and comparison with a recent ocean tide model. Geophys. J. Int. 2008, 173, 444-458. [CrossRef]

19. Yuan, L.; Ding, X.; Zhong, P.; Chen, W.; Huang, D. Estimates of ocean tide loading displacements and its impact on position time series in Hong Kong using a dense continuous GPS network. J. Geod. 2009, 83, 999-1015. [CrossRef]

20. Dong, D.; Fang, P.; Bock, Y.; Cheng, M.; Miyazaki, S. Anatomy of apparent seasonal variations from GPS-derived site position time series. J. Geophys. Res. 2002, 107, ETG9-1-ETG9-16. [CrossRef]

21. Zou, R.; Freymueller, J.; Ding, K.; Yang, S.; Wang, Q. Evaluating seasonal loading models and their impact on global and regional reference frame alignment. J. Geophys. Res. Solid Earth 2014, 119, 1337-1358. [CrossRef]

22. Yan, H.; Chen, W.; Zhu, Y.; Zhang, W.; Zhong, M. Contributions of thermal expansion of monuments and nearby bedrock to observed GPS height changes. Geophys. Res. Lett. 2009, 36, L13301. [CrossRef]

23. Fang, G.; Kwok, Y.; Yu, K.; Zhu, Y. Numerical simulation of principal tidal constituents in the South China Sea, Gulf of Tonkin and Gulf of Thailand. Cont. Shelf Res. 1999, 19, 845-869. [CrossRef]

24. Guo, J.; Yuan, Y.; Kong, Q.; Li, G.; Wang, F. Deformation caused by 2011 eastern Japan great earthquake monitored by GPS single-epoch precise point positioning technique. Appl. Geophys. 2012, 9, 483-493. [CrossRef]

25. Guo, J.; Dong, Z.; Tan, Z.; Liu, X.; Chen, C.; Hwang, C. A crossover adjustment for improving sea surface height mapping from in-situ high rate ship-borne GNSS data using PPP technique. Cont. Shelf Res. 2016, 125, 54-60. [CrossRef]

26. Petit, G.; Luzum, B. IERS Conventions. Bureau International Des Poids et Mesures Sevres (France). 2010. Available online: https://www.iers.org/IERS/EN/Publications/TechnicalNotes/tn36.html (accessed on 17 December 2020). 
27. Dill, R.; Dobslaw, H. Numerical simulations of global-scale high-resolution hydrological crustal deformations. J. Geophys. Res. Solid Earth 2013, 118, 5008-5017. [CrossRef]

28. Dill, R. Hydological model LSDM for operational earth rotation and gravity field variations. In Scientific Technical Report STR08/09; GFZ Potsdam: Potsdam, Germany, 2008.

29. Kang, S.; Chung, J.; Lee, S.; Yum, K. Seasonal variability of the M2 tide in the seas adjacent to Korea. Cont. Shelf Res. 1995, 15, 1087-1113. [CrossRef]

30. Jin, G.; Pan, H.; Zhang, Q.; Lv, X.; Zhao, W.; Gao, Y. Determination of harmonic parameters with temporal variations: An enhanced harmonic analysis algorithm and application to internal tidal currents in the South China Sea. J. Atmos. Ocean. Technol. 2018, 35, 1375-1398. [CrossRef]

31. Pan, H.; Lv, X.; Wang, Y.; Matte, P.; Chen, H.; Jin, G. Exploration of tidal-fluvial interaction in the Columbia River estuary using S_TIDE. J. Geophys. Res. Oceans 2018, 123, 6598-6619. [CrossRef]

32. Shen, Y.; Guo, J.; Liu, X.; Kong, Q.; Guo, L.; Li, W. Long-term prediction of polar motion using a combined SSA and ARMA model. J. Geod. 2018, 92, 333-343. [CrossRef]

33. Zhou, M.; Guo, J.; Liu, X.; Shen, Y.; Zhao, C. Crustal movement derived by GNSS technique considering common mode error with MSSA. Adv. Space Res. 2020, 66, 1819-1828. [CrossRef]

34. Foreman, M.; Cherniawsky, J.; Ballantyne, V. Versatile harmonic tidal analysis: Improvements and applications. J. Atmos. Ocean. Technol. 2009, 26, 806-817. [CrossRef]

35. Tazkia, A.; Krien, Y.; Durand, F.; Testut, L.; Islam, A.; Papa, F.; Bertin, X. Seasonal modulation of M2 tide in the Northern Bay of Bengal. Cont. Shelf Res. 2017, 137, 154-162. [CrossRef]

36. Kang, S.; Foreman, M.; Lie, H.; Lee, J.; Cherniawsky, J.; Yum, K. Two-layer tidal modeling of the Yellow and East China Seas with application to seasonal variability of the M2 tide. J. Geophys. Res. Oceans 2002, 107, 6-18. [CrossRef]

37. Müller, M. The influence of changing stratification conditions on barotropic tidal transport and its implications for seasonal and secular changes of tides. Cont. Shelf Res. 2012, 47, 107-118. [CrossRef]

38. King, M.; Williams, S. Apparent stability of GPS monumentation from short-baseline time series. J. Geophys. Res. Solid Earth 2009, 114, B10403. [CrossRef]

39. Zhou, M.; Liu, X.; Guo, J.; Jin, X.; Chang, X.; Ji, B. Ocean tide loading displacement parameters estimated from kinematic PPP-derived coordinate time series: Effect of mass loading in Hong Kong. IEEE J. Sel. Top. Appl. Earth Obs. Remote Sens. 2020, 13, 6064-6076. [CrossRef]

40. Fu, Y.; Freymueller, J.; Jensen, T. Seasonal hydrological loading in southern Alaska observed by GPS and GRACE. Geophys. Res. Lett. 2012, 39, L15310. [CrossRef]

41. Xiang, Y.; Yue, J.; Cong, K.; Xing, Y.; Cai, D. Characterizing the seasonal hydrological loading over the Asian continent using GPS, GRACE, and hydrological model. Pure Appl. Geophys. 2019, 176, 5051-5068. [CrossRef]

42. Petrov, L.; Boy, J. Study of the atmospheric pressure loading signal in very long baseline interferometry observations. J. Geophys. Res. 2004, 109, B03405. [CrossRef]

43. Wijaya, D.; Böhm, J.; Karbon, M.; Schuh, H. Atmospheric pressure loading. In Atmospheric Effects in Space Geodesy; Böhm, J., Schuh, H., Eds.; Springer: Berlin, Germany, 2013; pp. 137-157. [CrossRef]

44. Williams, S.; Penna, T. Non-tidal ocean loading effects on geodetic GPS heights. Geophys. Res. Lett. 2011, 38, L09314. [CrossRef]

45. Van Dam, T.; Collilieux, X.; Wuite, J.; Altamimi, Z.; Ray, J. Nontidal ocean loading: Amplitudes and potential effects in GPS height time series. J. Geod. 2012, 86, 1043-1057. [CrossRef] 